\title{
From thesis to publication of a paper: some ideas and suggestions
}

$\mathrm{T}$ o start with, I wish to emphasise that what I will say here refers to an already completed and approved thesis. It is not about planning a research project. To do this you need - first of all - a good question. And good questions are hard to come by to mortals like us. A lot of creativity and imagination is necessary. If you ask a silly question you will probably get a silly answer! For example, you may want to know if there is a reationship between inflation and the success of the Brazilian world cup squad! One consequence of this, at least for medicine, is that a research question or proposal requires almost as much time to prepare as doing the research itself, if not more. Bearing this in mind, let us now see what can be done to transform a thesis into a paper.

First and foremost, remember that writing a thesis has nothing to do with writing a manuscript to be submitted to a learned journal. In a thesis you are allowed to write almost as much as you like, or perhaps as much as your supervisor allows you to! A paper must be concise, clear and economical in space. In other words, if you can say something in one word do not use six. Editors of good journals have a sharp eye and will quickly spot the verbose and pompous writer. So, writing a paper from a thesis does not mean publishing a shortened version of the thesis. In fact, I am afraid it means starting almost from scratch. You need to select carefully the information you think deserves to be shown to the world; and you will quickly realize that there may not be a lot of it. In a thesis you are

*Professor Titular, UNIFESP-EPM. allowed to include almost everything you have done, right or wrong! Therefore you have to be ruthless with yourself and discard a lot of stuff you think is marvellous. This is a painful process, and please be prepared. Some of my students produce enormous masterpieces for their doctoral thesis but end up with papers of no more than 4 to 5 pages. If it is any consolation, remember that the seminal paper by Watson and Crick on the DNA double helix was little more than a page in the journal Nature. So, I repeat, be ruthless with yourself. The editor and referees will certainly be much more ruthless than you.

Thus, below are some points to remember. The sequence given is my own. People vary a lot in the way they tackle the art and craft of writing. However, one thing I know: nobody writes in the canonical sequence "Introduction, Material and Methods, Results and Discussion".

1. Keep a book or diary, and write down everything you have done in detail during the preparation of your thesis. Write down what you have discussed with colleagues, friends and whatever you have picked up from lectures and conferences. Conversation in a bar with well-disposed colleagues - preferably around a "bottle" - creates a congenial atmosphere for scientific endeavour! Writing helps you to think. Writing and thinking mutually interact. The discipline of formulating a thought into a sentence clarifies, sharpens and delimits the thought. Writing is like playing a musical instrument, i.e. you need to practice every day. Also, if you do not write, you forget. And if you have everything written down it will be easier to write the final manuscript. 
2. Write down possible titles, authors, and look at the proposed journal. This is a good exercise because you may visualise your paper published in front of you. The adrenaline will increase and you can imagine the whole word reading your masterpiece! Authors: indeed this is difficult to decide. Should you include your technician? Should you include your boss? What a dilemma! Multidisciplinary work means multiauthorship which in turn means that papers are becoming like ancient monuments, i.e. nobody knows who is the author. Some journals, however, require that all authors sign a document declaring that they have had full participation in the research. I am afraid this business is becoming a political-scientific game. There are no hard and fast rules.

3. Outline the theme of the paper in one page. This is the crunch. What was the question and what are the conclusions? Don't despair if you are not too clear about this. A lot of discoveries were made simply by serendipity. Your question may change as your research develops. However, depending upon the nature of the research, you may need precise questions and answers. Always keep an open mind.

4. Consult library references. It is assumed that you have an idea of the main references. Do not overdo it. If you read too much you will obliterate your brain with other people's ideas and there will be no space for your own. It is amazing how the brain enjoys the comfort of an explanation. Once you have an explanation your neurones get lazy. Read everything with a healthly critical mind. You must never read a paper as a believer. If you do so, you have surrendered your autonomy to the author and he will persuade you that the earth is flat.

5. Prepare tables, graphs, charts, photos and other illustrations. And here you should refrain from using computer gimmicks, pies, blocks or other artifacts to impress your readers. Only the naive and inexperienced may be taken in by such artifacts. Your illustrations must be clear and simple and without fireworks.

6. Write legends for the illustrations. These are the objective results you have and will form the basis for your descriptions. They will force you to realize what results you do have. Also, legends are easy to write and may therefore help you if you have a mental block. Legends must be self-explanatory and everything must be labelled correctly.

7. Write the results section. Having finished the legends you can now write the results clearly and precisely. Never ever give opinions, interpretations or speculations here. Results are for facts only. Every result must have a corresponding figure, table or chart and vice-versa. There is no room for results without presentation of evidence. Allow the facts to speak for themselves.

8. Write the Discussion. This is the most difficult part. Remember that the purpose of the Discussion is: (a) to discuss the work per se, (b) to relate and compare it to that of others, and (c) to relate to other concepts and ideas. Always start by demonstrating the validity of your methods and results. You cannot suggest a new idea, concept or explanation if your methods and results are not valid (evidence-based science or medicine!). Always state clearly what is fact and what is interpretation (fiction sometimes!). It is fatal to mix fact and fiction! Readers will tend to believe what you say if you make clear what is fact and what is fantasy! Also, always point out possible difficulties in your rationale. Again, readers will be sympathetic and think: "What an honest guy or girl! I think I can believe him/her!" You may speculate but remember what Charles Darwin said in his introduction to "The Origin of Species": - "After five years work I allowed myself to speculate on the subject, and drew up some short notes..."

9. Conclusion. This may do one of the following:(a) it confirms what everyone knows, (b) it confirms what people have suspected, or (c) it is new and has never been thought before - rare I must say - watch for signs of megalomania!

10. You may write Materials and Methods earlier or now. It is easy to write, and if you are stuck it may help you overcome your frustration. There will be plenty of it though.

11. Finally write the Introduction. This is indeed bizarre since it is somehow instinctive to think that one should write the Introduction first. Since one often starts with the wrong idea about the research undertaken it is easier to write the Introduction after the Discussion. The objectives may have changed, new things may have been found, and so on and so forth. The Introduction has to be interesting, hold the reader's attention and say why the work was done.

12. Summary. This is what will be read first. It should be factual, concise and informative. You will have to select only the extremely relevant and new points. Sometimes it is here that you find that you have not got much to say...

13. References. You don't need to quote everybody who worked in the field. You are allowed to select the papers that you think are most relevant and that satisfy your high standards and critical evaluation. 
14. Acknowledgements. Only acknowledge people who were really helpful. Do not thank your mother-in-law because she changed the nappies of your beloved son or daughter.

15. Write, re-write, revise and revise again. Oscar Wilde spent one full morning deciding whether a comma should be taken out from one of his poems or not. He removed it in the end, but came back in the afternoon to put it back again!

16. Shelve the manuscript for a while (7-15 days) and forget about it. Pick it up again and you will be amazed to find some wonderful writing and some absolutely awful writing. After continuous writing and thinking one may get blind spots and be no longer able to see even obvious contradictions. Keep calm and correct everything. Rewrite wherever necessary. Ask a friendly but critical colleague to read it.

17. Style. Well, this is a difficult one because you may not have style. However, it can be helped a little (a lot, some say) if you read good literature. Scientists are not usually good writers. I meet a lot of colleagues who often say that they hate writing but they love working in the lab. Reading good literature improves your ability to express yourself. 